\title{
Simulating traditional textile heritage motifs by applying CAD-CAM-CAE tool for furniture decoration
}

\author{
Antonela Lungu ${ }^{1}$, Antonius Androne ${ }^{1}$, Lidia Gurău ${ }^{1}$, and Camelia Coşereanu ${ }^{1, *}$ \\ ${ }^{1}$ Faculty of Furniture Design and Wood Engineering, "Transilvania" University of Brasov, B-dul \\ Eroilor, nr. 29, 500036, Brasov, Romania
}

\begin{abstract}
As an interaction of multiple domains including design, the furniture industry may valorise in furniture ornamentation the traditional motifs, and could encourage the creativity of designers to develop original products with a modern design, based on the digitalized technology. The article presents an example of applying CAD-CAM-CAE tools for analysing the possibility of transposing traditional motifs from the textile heritage to the furniture decoration, and to select the appropriate $\mathrm{CNC}$ routing method and tool in order to obtain an ornament as close as possible to the original one. Traditional motifs (rose, tulip, bird, North Star) selected from the textile heritage of Țara Bârsei - a historical and ethnographic region of Transylvania - were drawn in a digital format, using CorelDraw and AutoCAD programs, and then imported for a simulation of $\mathrm{CNC}$ routing process on wooden materials, using the software vCarvePro 9.519 developed by Vectric, with two types of tools and two processing methods, namely engraving (Engrave) and carving (VCarve). Following the simulation and the analysis of the obtained images, both visually and by ImageJ software, it was assessed which method is suitable for each ornament, considering also the processing times indicated by the simulation process of the models.
\end{abstract}

\section{Introduction}

The textile heritage is a component of the cultural identity of a nation and therefore, each generation has the duty to preserve it and to transmit it to the next generations. The textile heritage creates a sensitive, tactile and visual world and reflects the society values. It is also an indicator of changes in time with regard to raw materials, techniques and dyes. The finesse of the fabrics, their patterns and motifs indicates the way of dressing and living, traditional mentalities and new fashion trends for each historical period of time [1].

Considering that the main purpose of the textile conservators is to slow the process of deterioration, several researchers [2] conducted a study aimed at digitally reconstruction of old textile fragments. Their research explored whether modern high-tech applications, concerning three-dimensional visualization used predominantly in engineering can be

\footnotetext{
*Corresponding author: cboieriu@unitbv.ro
} 
employed to capture historic textile fragments, and thus to preserve and reconstruct their beauty for future generations and also for new uses in contemporary applications.

Advanced techniques have been also used to the reconstruction of mail armour in two ways: by using a rigid body simulation and a cloth simulation. The study approach was based on reverse engineering and CAD application. Their method uses parameterization, parametric 3D modelling and rigid body simulation to analyse and reconstruct mail armour, studying the mail armour at three levels: rings, mail fabric and mail garment [3].

The museum collections comprise objects that belong to the movable cultural heritage, including traditional textiles and costumes. Museum, as the main representative of the traditional culture, has the responsibility of researching and treasuring the objects in the best conservation conditions. An important role is assumed by the private collectors, who put effort and passion to form collections structured by groups specific to regions, types of objects or materials, with respect to each artefact's identity [4]. In this respect, textiles have been used and adapted in various applications and contexts, and have been always highly regarded amongst all members of society. Lately, their significance is more and more connected to the historical, economical and artistic background in which they were created or which they represent [5].

The best actual method for ensuring the continuity of traditional ornaments inspired from the historical textile heritage is their transposition into digital format as vector files. Thus, based on their multiple forms and design, the motifs become available for use in many other areas as modern textile, industrial embroidery, interior design, digital printing or graphics $[6,7]$.

The ornaments from the sewn or woven objects that belong to the textile heritage are two-dimensional objects, and for their digitization different software can be used. For example, traditional motifs collected from popular costumes from Crişana and Maramureş, regions of Romania were digitized using Geographic Information System (GIS) program, obtaining similar results to those from the use of specialized software in graphics, such as Inkscape, Adobe Illustrator or Corel Draw [8]. The CorelDraw vector graphics program was used to transpose the traditional motifs from the Transylvanian ethnographic area, preserving the symbolism and colour specific characteristic of the area. Further, a pattern was selected and embroidered by software on a women's jacket [6].

For 3D analysis and reconstruction of objects, a suitable method is reverse engineering (also known as backwards engineering or back engineering). It was used in developing and testing a method of shoe manufacturing lasts for bespoke shoe production using an additive manufacturing process [9], and as methodology and associated algorithm used for the automated design of products with high level of customization for which no documentation is available [10] or for re-manufacturing of mechanical components [11].

Industry 4.0, based on digitization and CAD-CAM-CAE technologies offers the opportunity to develop interdisciplinary studies and new applications for the appreciation and valorisation of these motifs. Therefore, furniture industry is an example for such kind of applications, where modern products with old decorations and symbols can be created and promoted as national identity representatives in furniture design.

The aim of this paper is to propose an analyse method for transposing the traditional motifs originated from an important textile heritage from Romania into furniture decoration, based on digital technologies and image analysis software, which provide the necessary information to select the right processing method and tool and to obtain the best variant of ornament from the aesthetic point of view, close to the original one. 


\section{Material and methods}

\subsection{Traditional motifs}

Țara Bârsei is a historical and ethnographic region of Transylvania, province of Romania. The richness of phytomorphic and zoomorphic ornaments and their symbolic interpretations originated from this region since the mid of 19th century can be seen nowadays in an old community from Şcheii Braşovului, where the textile heritage was very well preserved [12]. The preservation of the textile heritage from this community is largely due to the young people named "June", who organize an annual celebration, where they parade on horseback and are dressed in popular costumes. The traditional embroideries on their costumes include the floral motif representing the rose shown in Fig. 1a1.

For the phytomorphic motifs from Fig. 1b1, which are embroidered on the sleeve of a traditional woman's blouse named "ie", the symmetry and alternation laws are applied.

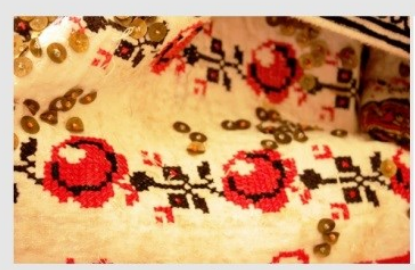

a1

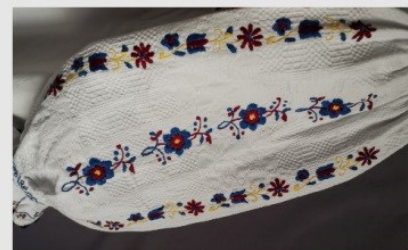

b1

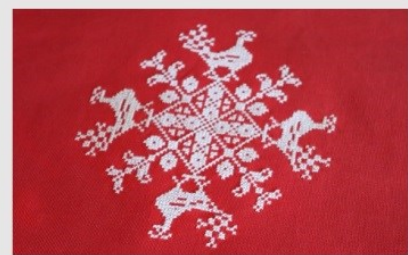

$\mathrm{cl}$

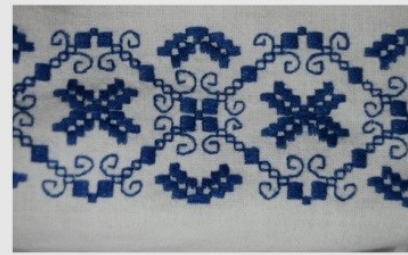

d1

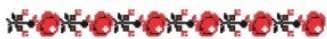

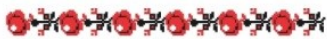

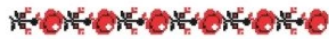

a2

\section{*

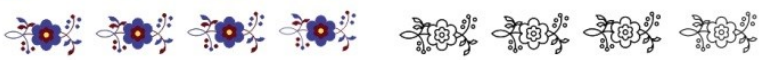

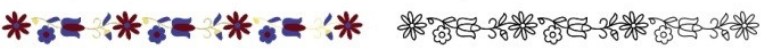

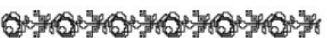

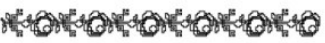

a3 b3

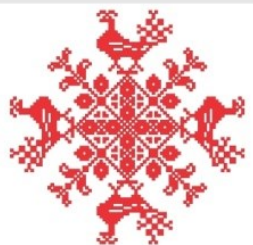

c2

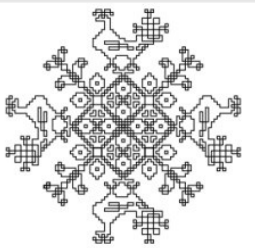

c3

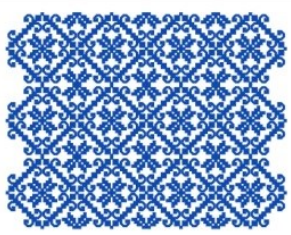

$\mathrm{d} 2$

Fig. 1. Traditional motifs from textile objects from Ţara Bârsei subjected to the present research: a Model 1, from Şcheii Braşovului; b - Model 2, from Făgăraş; c - Model 3, from Araci; d - Model 4, from Dumbrăviţa. 
In the traditional Romanian motifs, the zoomorphic ornaments are widely used, one of the most interesting representations being the world of birds, some of them being parts of geometric compositions [13]. In Fig. 1c1 it is represented a motif with four birds used as central ornament of tablecloths and wipes.

From the category of cosmomorphic ornaments, Fig. 1d1 shows the "North Star" motif, which is also named "The wing of the mill" or "The eight point star", collected from a woman's blouse originated from a Țara Bârsei's village.

The ornamental compositions of Fig. 1 were taken from objects belonging to private collections. The sewing techniques used are the basis for decorating the materials for pieces of traditional costumes or for decorating homes, respectively sewing in crosses on one side (a1 and c1), full embroidery on the drawing (b1) and full embroidery on the thread (d1).

\subsection{Methods and approach}

The four motifs selected from the cultural heritage of Țara Bârsei and presented in Fig. 1 were digitized and subjected to wood processing simulation and image investigation, following the steps below:

1. Digital drawing of the motifs using professional graphics software CorelDraw and export the files in AutoCAD.

2. Simulation of CNC routing on wood surface, using VCarvePro 9.519 software developed by Vectric.

3. Analysis and objective evaluation of the simulated processed surface, using ImageJ software.

CorelDraw software was used to draw the selected traditional motifs, maintaining their exact contour, scale and colours (Fig. 1a2, b2, c2 and d2). The drawings were saved as CDR vector file formats, then were converted to DXF files in AutoCAD (Fig. 1a3, b3, c3 and $\mathrm{d} 3$ ) and imported in VCarvePro 9.519 software for the simulation.

The simulation software allows two type of processing methods. Engrave is the processing methods with a constant cutting depth of $2 \mathrm{~mm}$ for contours, and can be applied to closed or opened contours of the drawing. V-Carve is the processing method with cutting depth between $1 \mathrm{~mm}$ to $3 \mathrm{~mm}$ for the surface and $2 \mathrm{~mm}$ for the contour. The second method can be applied only for closed contours of the drawings. The two methods can be combined in case of small contour lines.

A first step in the simulation of the milling operation on CNC router was the selection of the tools and set up their geometry, cutting parameters, feed speeds and rotation speed. The selection of the tools was made considering both the type of models to be processed, which required low cutting depths, and the feed speed during processing. The selected tools were $\mathrm{V}$ groove router bits with $90^{\circ}$ angle (Fig. 2a) and $120^{\circ}$ angle (Fig. 2b), suited for engraved surfaces. The parameters used for milling simulation are presented in Table 1.

Table 1. Milling parameters set up

\begin{tabular}{|c|c|c|c|c|c|}
\hline $\begin{array}{c}\text { Angle A, } \\
\text { degrees }\end{array}$ & $\begin{array}{c}\text { Diameter D, } \\
\mathrm{mm}\end{array}$ & $\begin{array}{c}\text { Spindle speed, } \\
\text { r.p.m. }\end{array}$ & $\begin{array}{c}\text { Pass depth, } \\
\mathrm{mm}\end{array}$ & $\begin{array}{c}\text { Feed rate, } \\
\mathrm{m} / \mathrm{min}\end{array}$ & $\begin{array}{c}\text { Plunge rate, } \\
\mathrm{m} / \mathrm{min}\end{array}$ \\
\hline 90 & 32 & 12000 & 2 & 3 & 0.9 \\
\hline 120 & 32 & 12000 & 2 & 3 & 0.9 \\
\hline
\end{tabular}




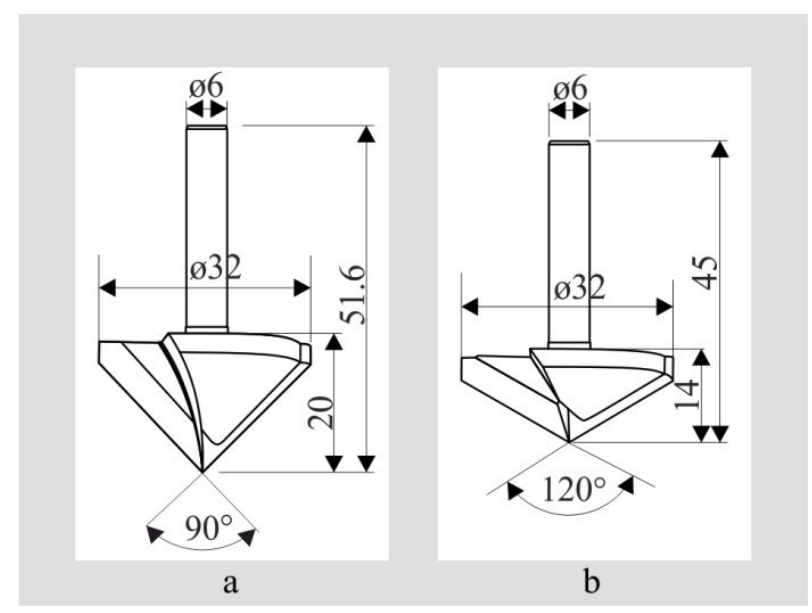

Fig. 2. Tools used: $\mathrm{a}-$ at $90^{\circ}$ angle; $\mathrm{b}-$ at $120^{\circ}$ angle.

\subsection{Image $J$ analysis}

The images resulted from the simulation process have been analysed by ImageJ software, an open source image processing program. ImageJ identifies the motifs as objects, selects the contours (based on a threshold on user's decision) and returns a mask image. Before measuring, a scale was set based on pixels for the length. Then, the colour image was converted into a grey scale and the contrast was enhanced. The software calculates the processed area $\left(\right.$ in $\mathrm{mm}^{2}$ ) and the percentage of the processed area from the total surface area.

\section{Results and discussion}

\subsection{Simulation of the milling process and visual analysis}

VCarvePro 9.519 software was used for the simulation of CNC router processing through engraving (Engrave) and carving (V-Carve) methods, resulting the images of the ornaments. The differences between the appearances of the ornaments in the two situations were highlighted.

The simulation of the first ornament (Model 1) with Engrave and V-Carve methods and with the two types of $\mathrm{V}$ tools angled at $90^{\circ}$ and $120^{\circ}$ respectively, had as result the images in Fig. 3.1. The simulation results have shown big differences between the details of the ornament when using Engrave and V-Carve processing methods. In the circled details from Fig. 3.1a2, b2, c2 and d2, these differences are more evident. The ornament simulated with V-Carve looks cleaner and finer than the engraved one, but comparing it with the detail from Fig. 3.2 it can be noticed that some of the lines are interrupted. Instead, no differences were observed for V-carved ornaments with the two types of tools. In case of the simulation with the Engrave method, the trace of the $120^{\circ}$ angled tool on the ornament looks wider than that of the $90^{\circ}$ angled tool.

The simulation of the tulip composition (Model 2) was conducted in the same conditions as for the previous one (Model 1), and had as result the images in Fig. 4.1. No discontinuities of the contour were noticed for this ornament. The differences between the four variants can be better analysed in the details from Fig. 4.1, for which a detail from the digitized model was extracted in Fig. 4.2. The simulation with Engrave and V-Carve 
methods generated approximately the same model for the same type of tool. The single difference is to be noticed in the central part of the flower. Instead, remarkable differences appear between the ornaments processed with different tools and the same method, in terms of width of the processed contour. The ornament simulated with tool angled at $90^{\circ}$ (Fig. 4.1 a1 and c1) looks cleaner and finer than that simulated with tool angled at $120^{\circ}$.

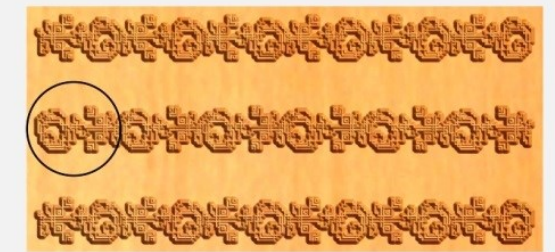

a1

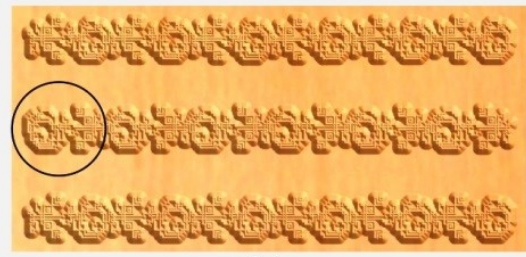

b1

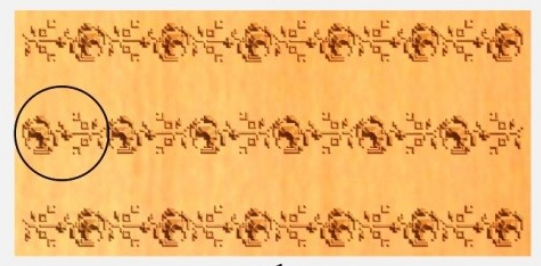

c1

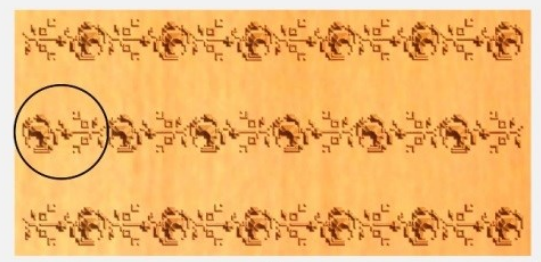

d1

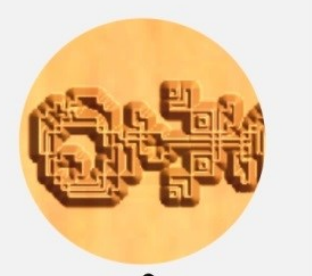

a2

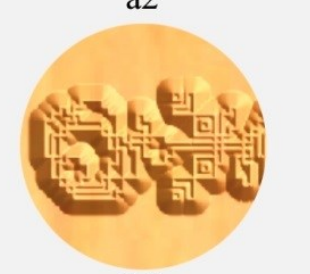

b2

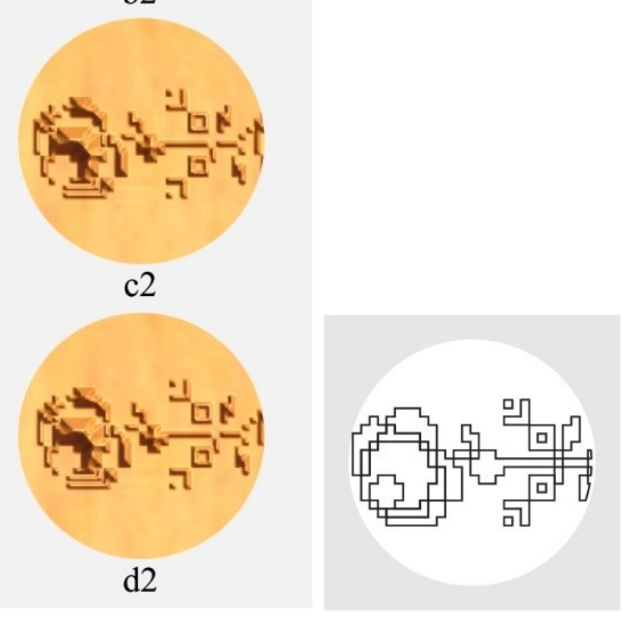

Fig. 3.1. (left) Simulation results for Model 1: a - Engrave $90^{\circ} ; \mathrm{b}$ - Engrave $120^{\circ} ; \mathrm{c}-\mathrm{V}$-Carve $90^{\circ} ; \mathrm{d}$ - V-Carve $120^{\circ}$.

Fig. 3.2. (right) Detail from the drawing of Model 1.

The two models (Model 1 and Model 2) analysed before are traditional motifs obtained by different techniques used to decorate the textile clothes. The first model was sewn in crosses technique and the second one was obtained by embroidery. The continuous line of the embroidery, as seen in the detail from Fig. 4.2. offers the possibility to apply both VCarve and Engrave methods for CNC routing, as the simulation results show, but the digitized Model 1 based on the crosses technique and subjected to simulation with V-Carve method presents discontinuities, which will make the ornament processed on the wood surfaces very little visible. 


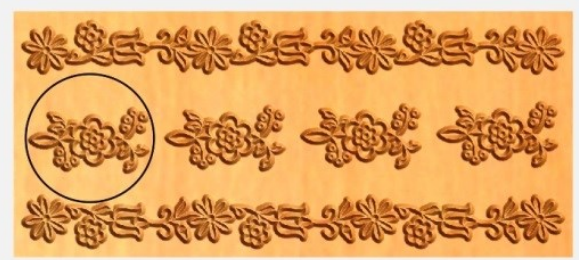

a1

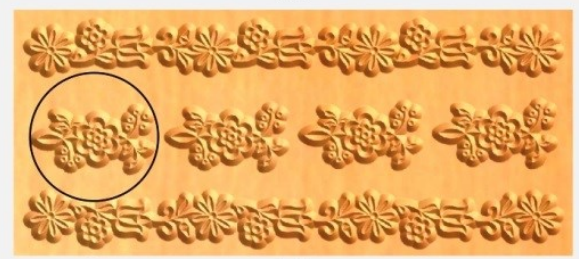

b1

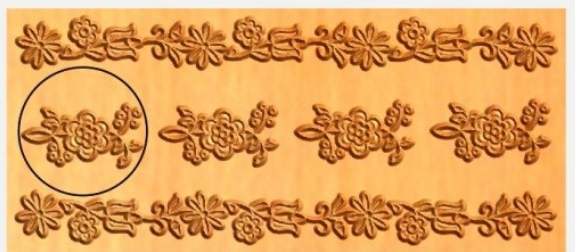

c1

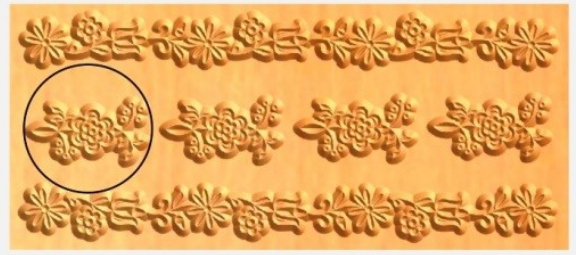

d1

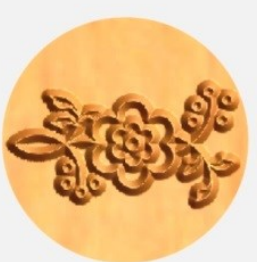

a2

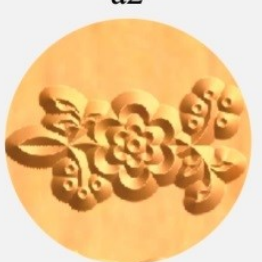

b2

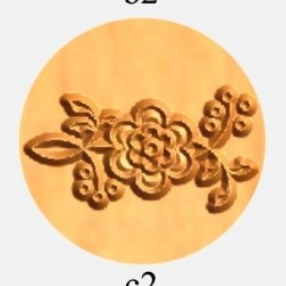

c2

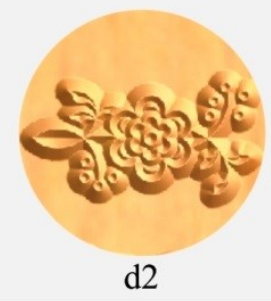

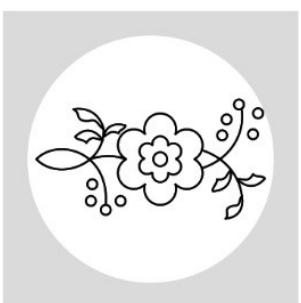

Fig. 4.1. (left) Simulation results for Model 2: a - Engrave $90^{\circ} ; \mathrm{b}-$ Engrave $120^{\circ} ; \mathrm{c}-\mathrm{V}-$ Carve $90^{\circ} ; \mathrm{d}$ - V-Carve $120^{\circ}$.

Fig. 4.2. (right) Detail from the drawing of Model 2.

The geometric motif with birds (Model 3) was simulated also with V-carve and Engrave methods, setting for the simulation the same tools, angled $90^{\circ}$ and $120^{\circ}$, respectively. The images resulted after simulations are presented in Fig. 5.1. The Engrave method highlights the contour of the ornament and just visible differences in width sizes were noticed for the simulations with the two different tools (Figs. 5.1 al and b1). For V-Carving simulation, similar to the case of Model 1, the ornament looks finer, but it is not as evident as in the case of applying Engrave method, and no differences were noticed for the two different tools (Figs. 5.1c1 and d1). This model obtained through crosses technique, has also discontinuities of the contour, so a combination of the two methods have been applied in the simulation of this model as a next step, for testing another method of milling on CNC Router. The ornament resulted from the combination of Engrave and V-Carve simulation (Figs. 5.1e1 and f1) looks similar with that resulted from engraving method. The details of the ornament presented in Fig. 5.1 can be compared to the detail from the drawing, presented in Fig. 5.2. Differences resulted from the simulation with the two different tools result in a wider processed area for Engraving, or combined method (V-Carve and Engrave) with $120^{\circ}$ angled tool. 


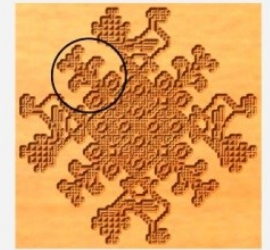

a1

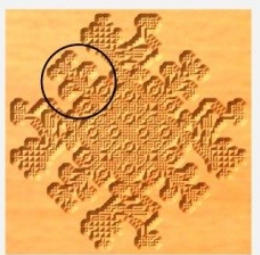

b1

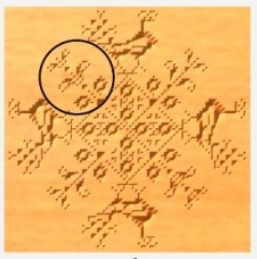

c1

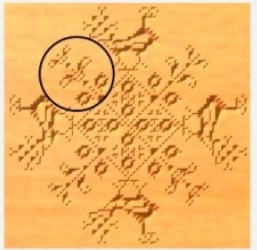

d1

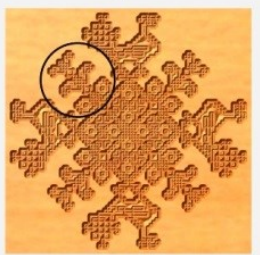

e1

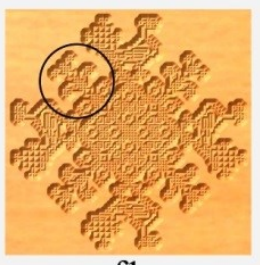

f1

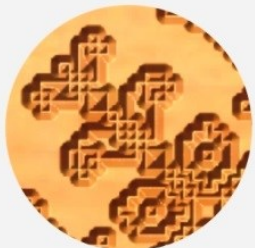

a2

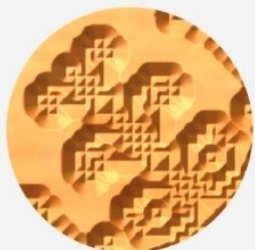

b2

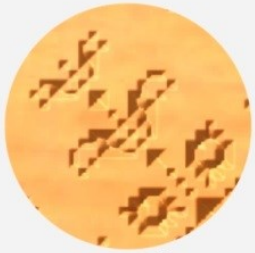

c2

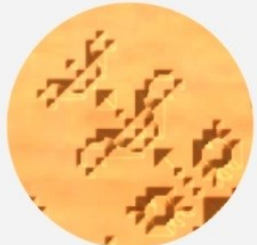

d2

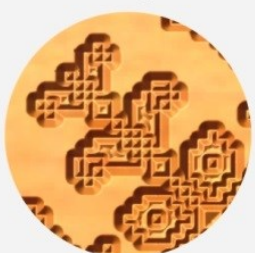

e2

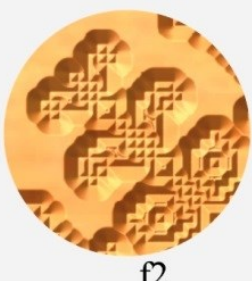

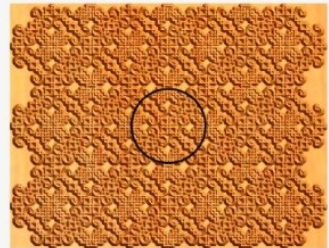

a1

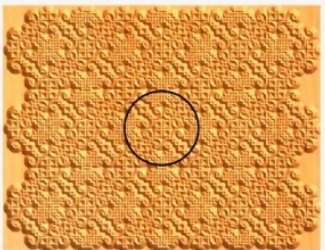

b1

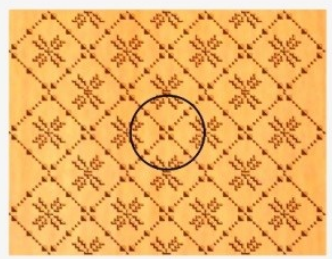

c1

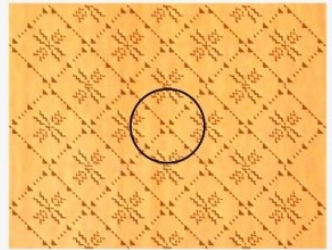

d1

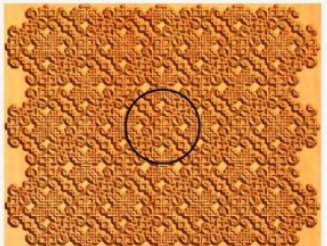

e1

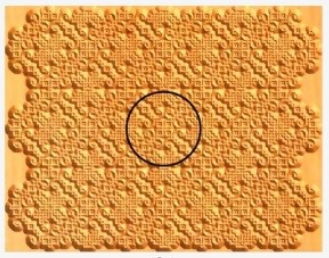

f1

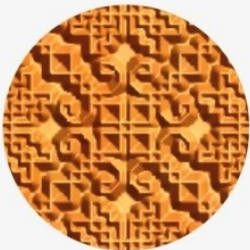

a2

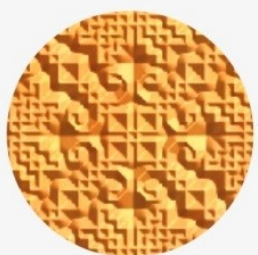

b2

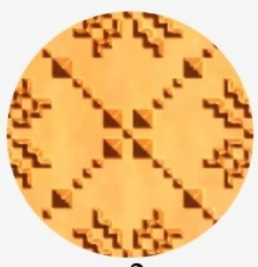

c2

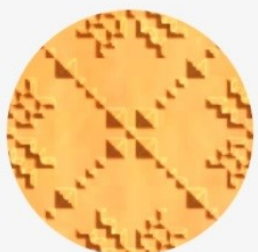

d2

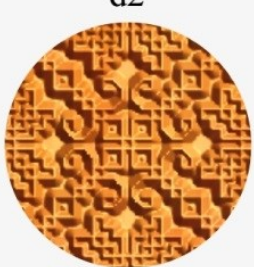

e2

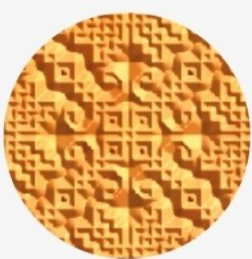

f2

Fig. 5.1. (left) Simulation results for Model 3: a - Engrave $90^{\circ} ; \mathrm{b}-$ Engrave $120^{\circ} ; \mathrm{c}-\mathrm{V}$-Carve $90^{\circ} ; \mathrm{d}$ - V-Carve $120^{\circ} ; \mathrm{e}-\mathrm{V}$-Carve and Engrave $90^{\circ}$; f - V-Carve and Engrave $120^{\circ}$.

Fig. 6.1. (right) Simulation results for Model 4: a - Engrave $90^{\circ} ; \mathrm{b}$ - Engrave $120^{\circ} ; \mathrm{c}-\mathrm{V}$-Carve $90^{\circ}$; $\mathrm{d}-\mathrm{V}$-Carve $120^{\circ}$; e-V-Carve and Engrave $90^{\circ} ; \mathrm{f}-\mathrm{V}$-Carve and Engrave $120^{\circ}$. 


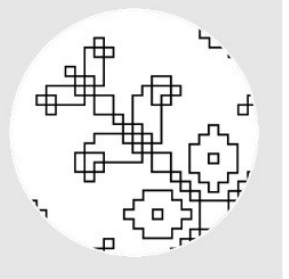

Fig. 5.2. Detail from the drawing of Model 3 .

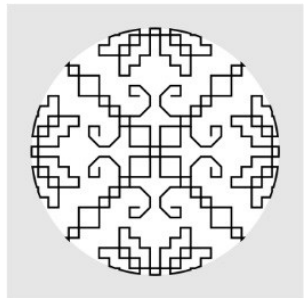

Fig. 6.2. Detail from the drawing of Model 4.

The geometric Model 4, digitized from a traditional motif obtained by full embroidery on the thread technique, was simulated with V-Carve, Engrave and the combined method (V-Carve and Engrave) between them. The images resulted from the simulations are presented in Fig. 6.1. The Engrave method applied in the simulation makes the ornament to look overcrowd, especially for the variant where the $120^{\circ}$ angled tool have been selected (Figs. 6a1 and b1). In case of applying V-Carve method (Figs. 6c1 and d1), the ornament looks incomplete and the lines present discontinuities of the contour, when compared to the original motif (Fig. 6.2). The combination of the two methods applied in simulation resulted in an overcrowd ornament, too. Combination of Engrave and V-Carve (Figs. 6.1e and 6.1f) methods creates the same appearance of the ornaments as with Engrave method. These versions don't create a clear image of the original ornament.

\subsection{Image J analysis}

When processing wood materials, both the material removed from the surface and the processing time are important, because they are connected to the tool wear and productivity.

An Image J analysis was performed on the ornaments images resulted in the simulation processes of milling on CNC Router the wooden materials. The ImageJ software output is the processed area value and the percentage of the processed area reported to the entire surface. The image analysis was completed afterwards with the processing times indicated by the simulation software. The masks resulted in ImageJ analysis are presented in Figs. 7, 8,9 and 10 .

The area and the percentage of the processed areas from the entire surfaces are presented in Table 2. The correlation between the processed area and the processing time for each model and method is shown in the diagram from Fig. 11.

Table 2. Images analysis results correlated with processing time

\begin{tabular}{|c|c|c|c|c|c|}
\hline \multirow{7}{*}{$\begin{array}{c}\text { Type of operation } \\
\text { Model }\end{array}$} & $\begin{array}{c}\text { Simulated } \\
\text { surface } \\
\text { size, } \\
\text { in mm }\end{array}$ & $\begin{array}{c}\text { Processed } \\
\text { area, } \\
\text { in } \mathrm{mm}^{2}\end{array}$ & $\begin{array}{c}\text { Percentage } \\
\text { of the } \\
\text { processed } \\
\text { area, } \\
\%\end{array}$ & $\begin{array}{c}\text { Processing } \\
\text { time, } \\
\text { in min:s }\end{array}$ \\
\cline { 2 - 6 } & Engrave $90^{\circ}$ & $104 \times 218$ & 4283.67 & 18.91 & $17: 30$ \\
\cline { 2 - 6 } & Engrave $120^{\circ}$ & $104 \times 218$ & 4472.26 & 19.74 & $12: 25$ \\
\cline { 2 - 6 } Model & V-Carve $90^{\circ}$ & $104 \times 218$ & 1696.38 & 7.49 & $18: 45$ \\
\cline { 2 - 6 } 2 & V-Carve $120^{\circ}$ & $104 \times 218$ & 1895.88 & 8.37 & $13: 35$ \\
\cline { 2 - 6 } & Engrave $90^{\circ}$ & $96 \times 218$ & 3311.00 & 15.82 & $08: 32$ \\
\cline { 2 - 6 } & Engrave $120^{\circ}$ & $96 \times 218$ & 3800.37 & 18.16 & $07: 38$ \\
\cline { 2 - 6 } & V-Carve $90^{\circ}$ & $96 \times 218$ & 3014.90 & 14.41 & $21: 59$ \\
\hline
\end{tabular}




\begin{tabular}{|c|c|c|c|c|c|}
\hline \multirow{4}{*}{$\begin{array}{c}\text { Model } \\
3\end{array}$} & Engrave $90^{\circ}$ & $193 \times 193$ & 7257.01 & 19.48 & $09: 02$ \\
\cline { 2 - 6 } & Engrave $120^{\circ}$ & $193 \times 193$ & 7783.68 & 20.89 & $07: 58$ \\
\cline { 2 - 6 } & V-Carve 90 $90^{\circ}$ & $193 \times 193$ & 3580.52 & 9.61 & $12: 37$ \\
\cline { 2 - 6 } & V-Carve $120^{\circ}$ & $193 \times 193$ & 3733.99 & 10.02 & $11: 07$ \\
\cline { 2 - 6 } & Combined 90 & $193 \times 193$ & 6923.38 & 18.58 & $21: 39$ \\
\cline { 2 - 6 } Model & Combined $120^{\circ}$ & $193 \times 193$ & 7287.30 & 19.56 & $18: 05$ \\
\cline { 2 - 6 } 4 & Engrave 90 $90^{\circ}$ & $128 \times 165$ & 7102.36 & 33.63 & $27: 06$ \\
\cline { 2 - 6 } & Engrave $120^{\circ}$ & $128 \times 165$ & 7328.15 & 34.70 & $24: 54$ \\
\cline { 2 - 6 } & V-Carve 90 $90^{\circ}$ & $128 \times 165$ & 2254.17 & 10.67 & $26: 32$ \\
\cline { 2 - 6 } & V-Carve $120^{\circ}$ & $128 \times 165$ & 2337.40 & 11.07 & $21: 19$ \\
\cline { 2 - 6 } & Combined 90 $90^{\circ}$ & $128 \times 165$ & 6579.55 & 31.15 & $53: 38$ \\
\hline & Combined $120^{\circ}$ & $128 \times 165$ & 8308.29 & 39.32 & $46: 13$ \\
\hline
\end{tabular}

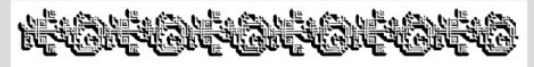

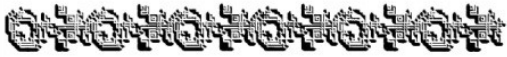

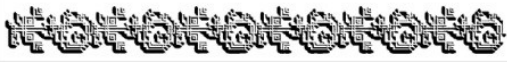
a

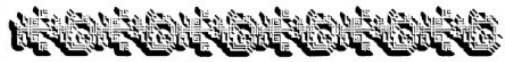

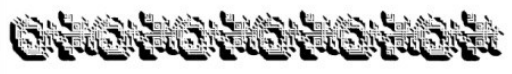

tros b

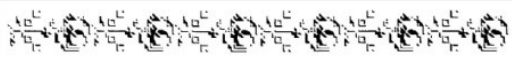

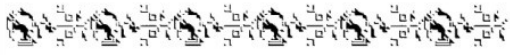

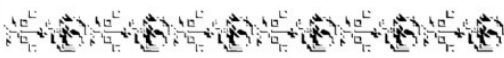
c

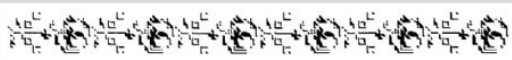

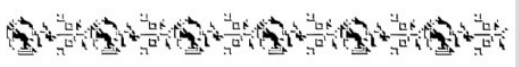

绕 6 to d

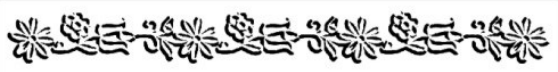

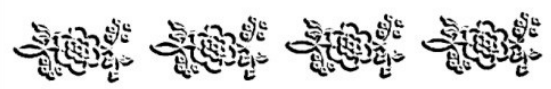

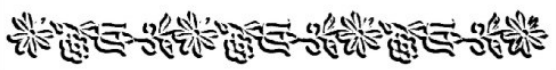

a

\section{윤.}

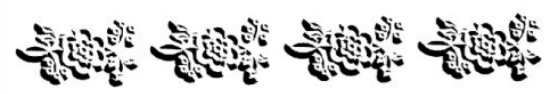

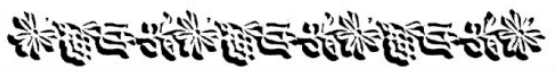

b

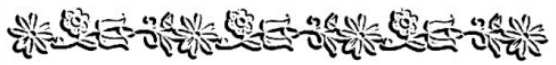

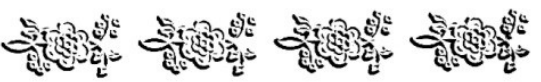

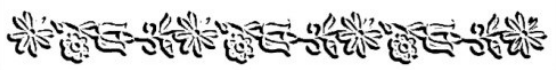

c

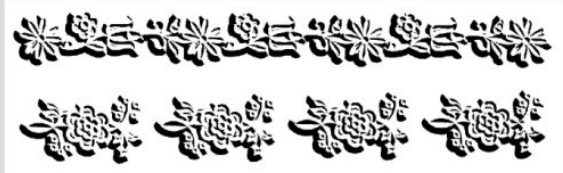

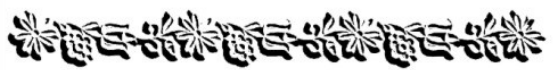

d

Fig. 7. (left) ImageJ masks for Model 1: a - Engrave $90^{\circ} ; \mathrm{b}$ - Engrave $120^{\circ} ; \mathrm{c}-\mathrm{V}$-Carve $90^{\circ} ; \mathrm{d}-\mathrm{V}-$ Carve $120^{\circ}$.

Fig. 8. (right) ImageJ masks for Model 2: a - Engrave $90^{\circ} ; \mathrm{b}-$ Engrave $120^{\circ} ; \mathrm{c}-\mathrm{V}$-Carve $90^{\circ} ; \mathrm{d}-$ V-Carve $120^{\circ}$. 


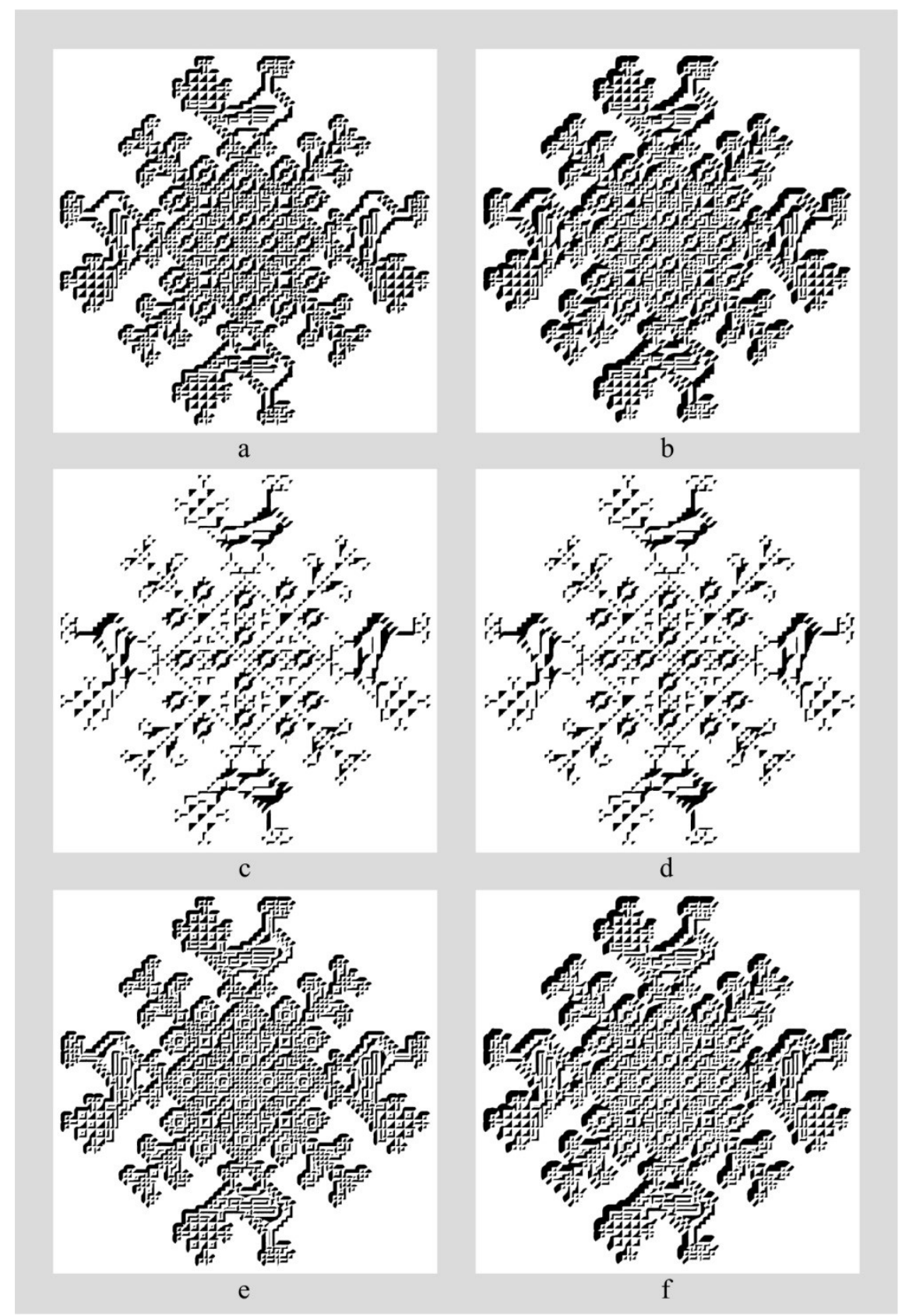

Fig. 9. ImageJ masks for Model 3: a - Engrave $90^{\circ} ; \mathrm{b}$ - Engrave $120^{\circ} ; \mathrm{c}-\mathrm{V}$-Carve $90^{\circ} ; \mathrm{d}-\mathrm{V}$-Carve $120^{\circ}$; e - V-Carve and Engrave $90^{\circ} ; \mathrm{f}-\mathrm{V}$-Carve and Engrave $120^{\circ}$. 


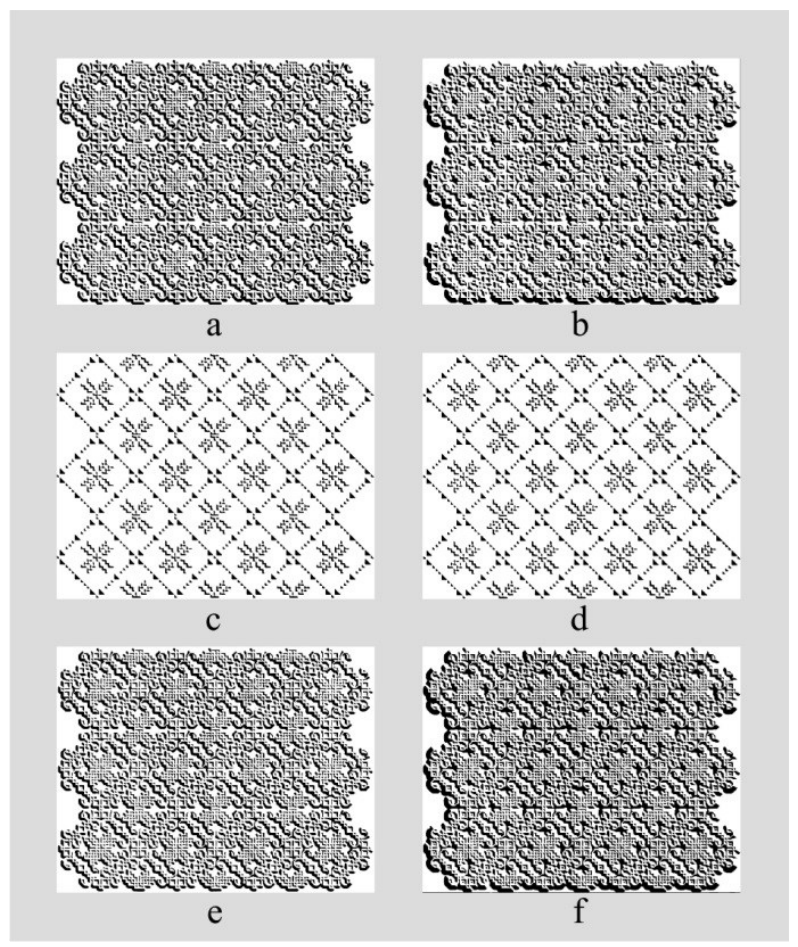

Fig. 10. ImageJ masks for Model $4: \mathrm{a}$ - Engrave $90^{\circ} ; \mathrm{b}$ - Engrave $120^{\circ} ; \mathrm{c}-\mathrm{V}$-Carve $90^{\circ} ; \mathrm{d}-\mathrm{V}$ Carve $120^{\circ}$; e - V-Carve and Engrave $90^{\circ} ; \mathrm{f}-\mathrm{V}$-Carve and Engrave $120^{\circ}$.

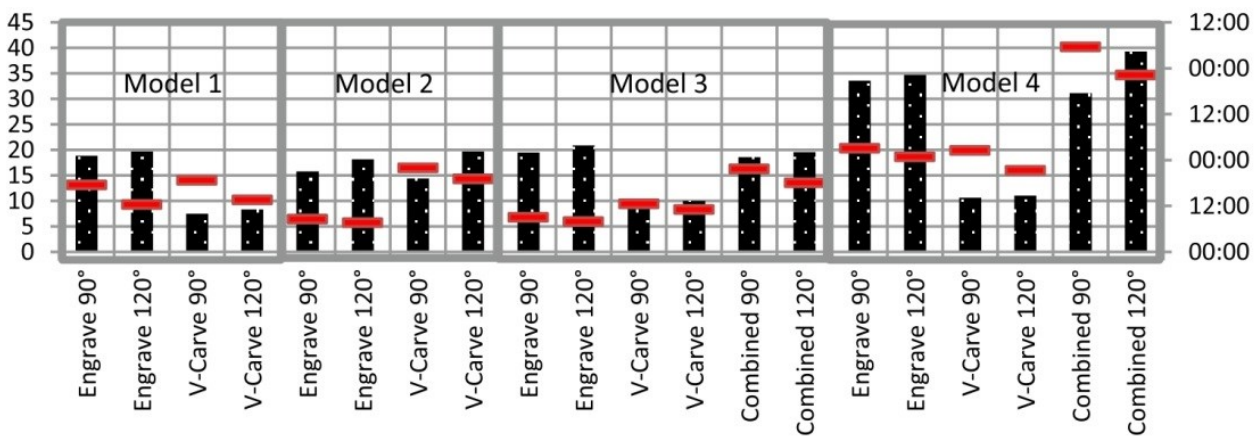

Percentage of the processed area, \% - Processing time, in min:s

Fig. 11. Correlation between processed area and processing time.

As shown in the diagram from Fig. 11, when applying V-Carve method, the smallest processed area is obtained, but the processing times are longer than in the case of applying Engrave method. This rule is applied for all models where the crosses technique was used for the textile motifs, but the images resulted through routing simulation with V-Carve method have shown discontinuities of the contour, so this method is not indicated for this type of models.

In case of Model 2, obtained from an embroidered textile motif, no large differences were observed between the processed areas of the ornaments with the same tool and different methods, but the processing times in case of using V-Carve method are significant 
longer than for using Engrave method. Comparing the processing times when applying Engrave method with the two different tools, a small difference of one minute resulted in favour of $120^{\circ}$ angled tool, so the selection of the tool can be done comparing the aesthetic appearance of the ornament.

The larger processed area and also the longest processing times are obtained for the combined method (V-Carve and Engrave). From the aesthetic point of view, the ornaments processed with the combined method are similar to those where Engrave method was applied. For the reasons presented before, the combination of Engrave and V-Carve method is not recommended to be used for routing the ornaments on wood surfaces.

Even if the processed area is larger when using $120^{\circ}$ angled tool compared to $90^{\circ}$ angled tool, the processing times are shorter in this case, so routing with $120^{\circ}$ angled tool is the fastest process.

As a compromise between the tool, processing method and aesthetic of the ornament, Engrave method can be choose to process the models where crosses technique (Model 1 and Model 3) or embroidery on the thread technique (Model 4) was used for the textile motifs, but the selection of the processing tool has to establish which characteristic prevails: is it the aesthetic of the ornament, or the shorter processing time? When using $120^{\circ}$ angled tool, a shorter processing time is obtained, but from the aesthetic point of view engraving with $90^{\circ}$ angled could be the most appropriate choice for transposing the motif on the furniture surface.

The compromise in case of Model 2 (for which the embroidery technique was used for the textile motif) could be done between Engrave and V-Carve methods, when using $90^{\circ}$ angled tool. From the aesthetic point of view, when applying Engrave and V-Carve methods with $90^{\circ}$ angled tool, the ornament looks better than in the case when $120^{\circ}$ angled tool is used. Due to its shortest processing time, Engrave method with $90^{\circ}$ angled tool is the compromise between the aesthetics and routing process efficiency in this case.

\section{Conclusions}

The richness of Romania's textile heritage represents, through its traditional motifs, a large study field and a source of inspiration for the creative industry, supported by digital technologies and CAD-CAM-CAE methods.

The study presents the methods and protocol to be followed based on advanced software tools for the selection of the appropriate $\mathrm{CNC}$ routing method and milling tool in order to transfer the traditional motifs collected from the textile heritage to the ornamentation of the furniture wooden surfaces.

Among over 100 traditional motifs having a symbol value originated from Țara Bârsei and collected from the textile heritage in an intensive research process, four models were digitized in vector format for this study using professional graphics software CorelDraw, then imported in AutoCAD and transferred to VCarvePro 9.519 software for the simulation of the $\mathrm{CNC}$ routing process using two $\mathrm{V}$-angled tools at $90^{\circ}$ and $120^{\circ}$ respectively, and two processing methods (Engrave and V-Carve). The analysis performed afterwards with ImageJ software had as results the calculation of the total processed area and its percentage from the total surface.

The simulation process is not only a good assessment method to be used for the visualisation of the aesthetic of the processed ornament with various methods, parameters and tools, but offers also an evaluation of the processing time, which is an important indicator of the productivity. The tool wear is another important factor in the industrial process, so offering data about the amount of wooden material removed during the CNC routing operation by applying a non-destructive method like ImageJ software will complete the analysis. Thus, the results of simulation software and image analysis may be used to 
select the appropriate $\mathrm{CNC}$ routing method and tool to be used in order to obtain the best variant of ornament from the aesthetic point of view. The analyse performed in this study shows that the technique of making the textile motif and implicitly the method of transposing it into the drawing format has influence on the selection of the $\mathrm{CNC}$ routing method, so it is possible, after investigation of other motifs, to find a common recommendation for those obtained by the same technique.

In order to validate the conclusions of the present study, further experimental research will investigate the quality of the processed surfaces by $\mathrm{CNC}$ routing the ornaments with the selected methods and tools, using different species of wood or engineered materials used for furniture manufacturing.

The data presented in this article constitute the preliminary study of the research work for Antonela Lungu's PhD thesis, in which Perspectives on the Development in Furniture of Some Traditional Romanian Motifs of Textile Heritage from Ţara Bârsei and its Surroundings will be continued, through experimental research on quality analysis surfaces obtained by milling following the combination of several working parameters.

The authors thank the private collections for granting the opportunity to examine their traditional items and also are grateful to Melinda Puskás for her support.

\section{References}

1. Ghidul Muzeului de Etnografie Braşov: patrimoniul textile (Monitorul Oficial R.A., Bucureşti, 2019)

2. S. Calvert, J. Power, H. Ryall, P. Bills, J. Writ. Creative Pract., 7(3), 415-425 (2014)

3. M. A. Wijnhovena, A. Moskvinb, Journal of Cultural Heritage, 45, 221-233 (2020)

4. F. Zaharia, Mioriţa. Revistă de etnografie şi folclor, 26, 10-14 (2020)

5. A. Serrano, M. J. Ferreira, E. C. de Groot, A. J, Cruz, Conservar Património, 31, 13-15 (2019)

6. L. Doble, O. Stan, M. D. Suteu, A. Albu, G. Bohm, A. Tsatsarou-Michalaki, E. Gialinou, AUTEX 2017, Romanian traditional motif - element of modernity in clothing (Corfu, Greece, 2017)

7. A. Lungu, M. Puskás, C. Coşereanu, RCIC'20, Convergences between the traditional motifs of the Romanian and Mexican textile heritage (Cluj, Romania, 2020)

8. L. Indrie, Z. Zlatev, D.C. Ilieş, A. Sturza, M. Dochia, M. Gozner, G. Herman, T. Caciora, Industria Textilă, 71(5), 492-498 (2020)

9. C. Amza, A. Zapciu, D. Popescu, MSE 2019, 3D-Printed shoe last for bespoke shoe manufacturing (Sibiu, Romania, 2019)

10. R. Pescaru, P. Kzratsis, G. Oancea, IManEE 2016, A Case Study of Reverse Engineering Integrated in an Automated Design Process (Kozani, Greece, 2016)

11. S. Ali, A. Durupt, P.A. Adragna, CIRP 2013, Reverse Engineering for Manufacturing Approach: Based on the Combination of $3 D$ and Knowledge Information (Bochum, Germany, 2013)

12. E. Antoni, P. Binder, P. Boca, R. Capesius, M. Dunăre, N. Dunăre, A. Eichhorn, L. Ghergariu, I. Hozoc, C. Irimie, M. Nistor, P. Petrescu, A. Seres, L. Someşan, J. Szentimrei, Tara Bârsei (Editura Academiei Republicii Socialiste România, Bucureşti, 1974)

13. N. Dunăre, Ornamentică tradițională comparată (Editura Meridiane, București, 1979) 